\title{
Magnesium Sulfate Therapy Is of Mild Benefit to Young Rats with Kaolin-Induced Hydrocephalus
}

\author{
OSAAMA H. KHAN, TERRY ENNO, AND MARC R. DEL BIGIO \\ Department of Pathology, University of Manitoba [M.R.D.B.] and Manitoba Institute for Child Health \\ [O.K., T.E.], Winnipeg, Manitoba, Canada
}

\begin{abstract}
Hydrocephalus causes damage to periventricular white matter at least in part through chronic ischemia. Magnesium sulfate $\left(\mathrm{MgSO}_{4}\right)$ has been shown to be protective in various models of neurologic injury. We hypothesized that this agent would ameliorate the effects of experimental childhood-onset hydrocephalus. Hydrocephalus was induced in 3- and 4-wk-old rats by injection of kaolin into the cisterna magna. Tests of cognitive and motor function were performed on a weekly basis. In a blinded and randomized manner, $\mathrm{MgSO}_{4}$ was administered in two separate experiments (s.c. injection $0.85,4.1$, or $8.2 \mathrm{mM} / \mathrm{kg} / \mathrm{d}$ ), supplemented by osmotic minipump infusion $(0.03 \mathrm{mM} / \mathrm{d})$ to prevent low trough levels for $2 \mathrm{wk}$, beginning $2 \mathrm{wk}$ after induction of hydrocephalus. The brains were then subjected to histopathological and biochemical analyses. With the $4.1 \mathrm{mM} /$ $\mathrm{kg} / \mathrm{d}$ dose, serum $\mathrm{Mg}^{++}$levels were elevated transiently from 1.3 to $\sim 7 \mathrm{mM} / \mathrm{L}$. We observed statistically significant improvement in gait performance and reduced astroglial reaction. There was also a trend to improved memory performance, but no evidence
\end{abstract}

of increased myelin or synaptic protein content. The $8.2 \mathrm{mM} /$ $\mathrm{kg} / \mathrm{d}$ dose was associated with sedation and there was no evidence of improvement in any parameter. We conclude that $\mathrm{MgSO}_{4}$ might be mildly protective in experimental hydrocephalus. (Pediatr Res 53: 970-976, 2003)
$\mathrm{Ca}^{++}$, calcium

\section{Abbreviations}
CGalT, ceramide galactosyltransferase
CSF, cerebrospinal fluid
GFAP, glial fibrillary protein
$\mathrm{Mg}^{++}$, magnesium ion
$\mathbf{M g S O}_{4}$, magnesium sulfate
MR, magnetic resonance
MBP, myelin basic protein
NMDA, $N$-methyl-D-aspartate
PNPP, $p$-nitrophenylphosphorylcholine phosphocholine
phosphodiesterase

Hydrocephalus is a common neurologic condition characterized by pathologic dilation of the cerebral ventricles. It is usually caused by obstruction of cerebrospinal fluid (CSF) flow. Axon damage in the periventricular white matter is one of the earliest pathologic consequences of ventricular dilation in humans and animals (1). The pathophysiology of hydrocephalus-induced brain damage is multifactorial, with contributions made by gradual physical stretching, compression, ischemia and possible accumulation of metabolic waste products (2). It has been postulated that physical trauma and ischemic injury to axons combine to alter membrane permeability leading to local influx of calcium and activation of calpains, which can cause proteolytic damage to the axonal cytoskeleton (3).

Received July 4, 2002; accepted January 8, 2003.

Correspondence: Marc R. Del Bigio, M.D., Ph.D., FRCPC, Department of Pathology, University of Manitoba, 770 Bannatyne Avenue, Winnipeg MB R3E 0W3, Canada; e-mail delbigi@cc.umanitoba.ca

This work was funded by a grant from the Canadian Institutes of Health Research. Dr. Del Bigio has a salary award from the Manitoba Medical Services Foundation (MMSF Clinical Research Professorship). Mr. Khan holds a summer studentship award from the Children's Hospital Foundation.

DOI: 10.1203/01.PDR.0000061561.42921.5B
Magnesium is a calcium antagonist that blocks NMDA channel receptors in a voltage dependent manner, as well as voltage and receptor-operated calcium channels $(4,5)$. Magnesium sulfate therapy reduces lipid peroxidation after experimental spinal cord injury (6), long-term hypoxic-ischemic brain damage in 7-d-old rat (7), and the volume of traumatic brain lesions (8). It also facilitates recovery of function following electrolytic cortical injury (9). Magnesium may act as a cerebral vasodilator thereby improving the cerebral circulation (10) and preventing cell damage. Clinically, magnesium sulfate is used for seizure prophylaxis in the management of pregnant women with eclampsia. Some reports suggest that this treatment is associated with reduced incidence of cerebral palsy in low birth weight infants (11).

In an experimental model of hydrocephalus induced by injection of kaolin into the cisterna magna of immature rats we have previously demonstrated the presence of abnormal quantities of soluble ionic calcium and activated calpains in the periventricular white matter (3). Diminished blood flow has been demonstrated in the white matter of hydrocephalic rats (12). We hypothesized that administration of magnesium sul- 
fate to young rats could ameliorate the abnormalities associated with moderate to severe early onset hydrocephalus.

\section{METHODS}

All animals were treated in accordance with guidelines set forth by the Canadian Council on Animal Care. The experiments were approved by the local animal use committee. All efforts were made to minimize suffering and the number of animals used. The experimental protocol is summarized in Fig. 1 and detailed below.

Animal preparation. Sprague Dawley rats were bred locally and 62 males were delivered after weaning at age $3 \mathrm{wk}$ (weight 39-63 g). In the 1st experiment behavior testing was done before hydrocephalus induction. In the 2nd experiment rats were injected with kaolin immediately upon arrival, effectively 1 wk earlier than in the first experiment. Anesthesia was induced by intramuscular injection of ketamine/xylazine (90/5 $\mathrm{mg} / \mathrm{kg}$ ). The neck was shaved and, under aseptic conditions, a 27 -gauge needle was inserted percutaneously into the cisterna magna. Sterile kaolin suspension $(0.04 \mathrm{~mL} ; 250 \mathrm{mg} / \mathrm{mL}$ in $0.9 \%$ saline) was injected slowly to induce hydrocephalus. In response to this quantity of kaolin, young rats experience gross enlargement of the cerebral ventricles and head and typically die within $6 \mathrm{wk}$. Controls received a sham injection with needle insertion only. Blood samples were taken from the tip of the rat's tail under anesthesia before kaolin injection to obtain a baseline serum magnesium level (using Hitachi 737 Clinical Chemistry Autoanalyzer). Two to three rats were housed in standard cages and provided with a normal 12-h day/night lighting schedule with free access to water and pelleted food. As the rats became impaired, moistened food and water were provided on the cage floors.

Magnetic resonance imaging and assignment to treatment group. Magnetic resonance (MR) studies were performed using a Bruker Biospec/3 MR scanner equipped with a 21-cm bore magnet operating at a field of $7 \mathrm{~T}$ (Karlsruhe, Germany) to obtain $\mathrm{T}_{2}$-weighted images of the brain in the coronal plane. The widths of the lateral ventricles and cerebrum were measured in the rostral cerebrum immediately anterior to the third ventricle. Frontal horn size was expressed as a ratio determined by dividing the total width of the ventricles by the width of the cerebrum. These methods have been previously described in detail $(13,14)$. Rats underwent MR imaging no more than $24 \mathrm{~h}$ before commencement of drug treatments. After imaging (Fig. 2 ), the rats were stratified according to ventricle size index and assigned alternatively to drug treatment or control groups. Rats underwent MR imaging $2 \mathrm{wk}$ later, no more than $24 \mathrm{~h}$ before sacrifice.
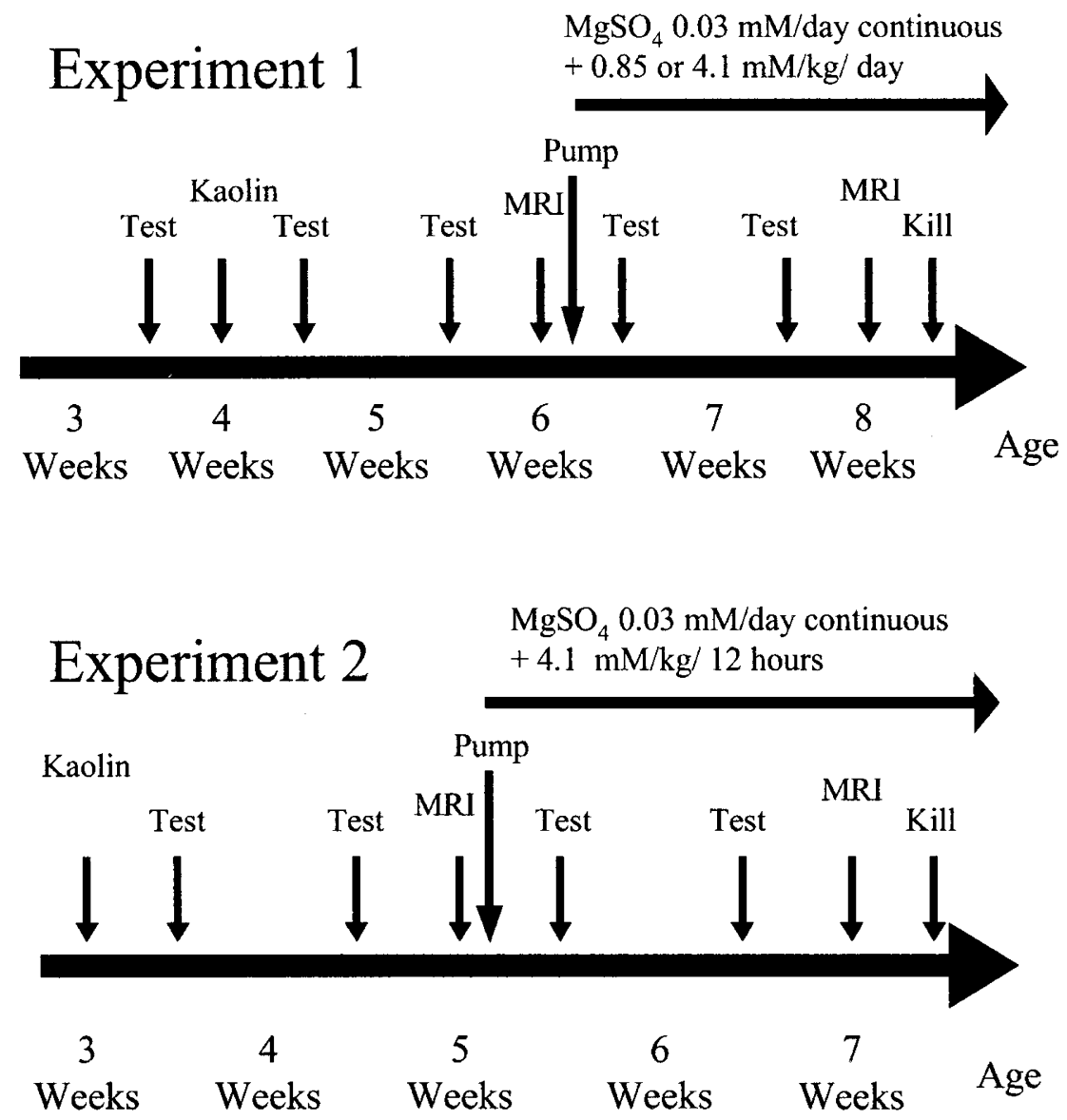

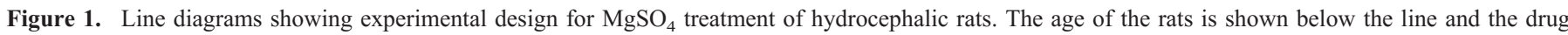

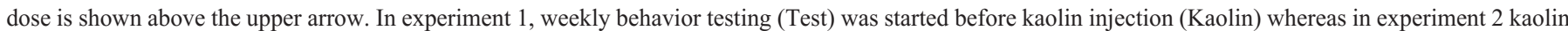

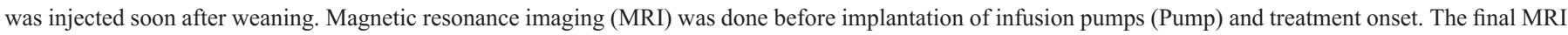
was done no more than $24 \mathrm{~h}$ before sacrifice (Kill). 


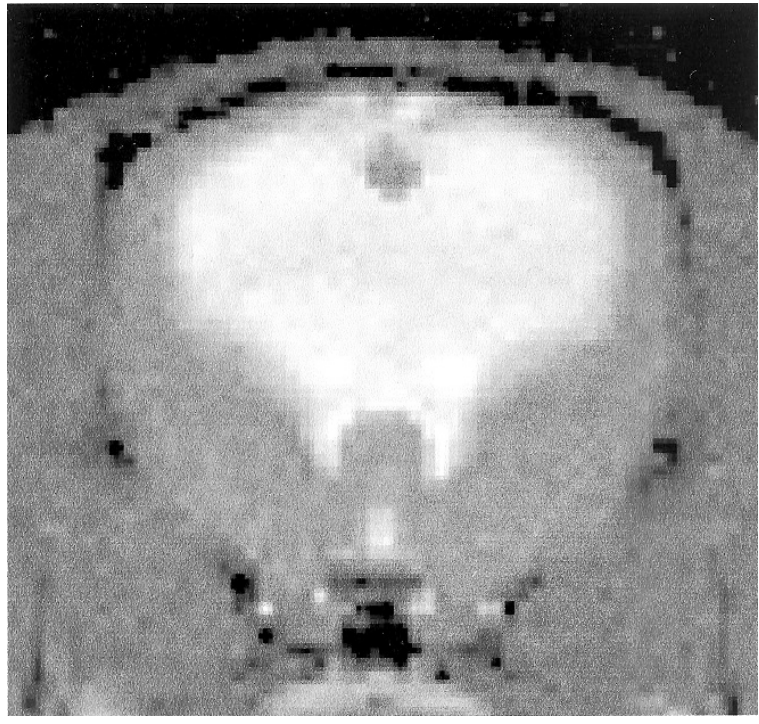

Figure 2. A typical magnetic resonance image (T2-weighted) through the frontal cerebrum (coronal slice) of a hydrocephalic rat at the end of experiment 2. Moderately severe ventricular enlargement is apparent.

Preparation and administration of $\mathbf{M g S O}_{4}$. In previously published work, short-term administration of $2.2-2.5 \mathrm{mM} / \mathrm{kg} / \mathrm{d}$ $\mathrm{MgSO}_{4}$ benefited young rats with hypoxic-ischemic brain injury $(7,15)$ and $2.2-5.0 \mathrm{mM} / \mathrm{kg} / \mathrm{d}$ benefited adult rats with quinolinate or hypoglycemia-induced brain injury (16-18). Magnesium sulfate has a short half-life after bolus administration therefore we wanted to prevent low trough levels by continuous administration via osmotic minipumps. Sterile solutions of high $(2.4 \mathrm{mM}$, saturated) and low dose $(0.5 \mathrm{mM})$ $\mathrm{MgSO}_{4}$ and saline control $(2.4 \mathrm{mM})$ were prepared. Osmotic minipumps (Alzet model 2002, rated at $12.5 \mu \mathrm{L} / \mathrm{d} \times 14 \mathrm{~d}$; DURECT Corp., Cupertino CA, U.S.A.) delivered the high dose solution at $0.03 \mathrm{mM} / \mathrm{d}$. Assuming body weights of $\sim 160 \mathrm{~g}$ at the onset of treatment, this equals $0.2 \mathrm{mM} / \mathrm{kg} / \mathrm{d}$. Osmotic minipumps were preloaded by the senior author and provided to the animal handlers in a blinded manner. The rats were anesthetized with ketamine/xylazine and pumps were implanted s.c. on the back under aseptic conditions. The treatment code was not broken until all behavioral, structural, and biochemical analyses were complete. To achieve doses comparable to those therapeutic in other studies, we needed to add supplemental boluses daily. Using the same solutions, syringes were loaded in a blinded manner and 0.85 or $4.1 \mathrm{mM} / \mathrm{kg} / \mathrm{d}$ was injected s.c. every morning. Tail blood was obtained various times after injection at the time of sacrifice to determine roughly the kinetics of magnesium in blood. In experiment 1 a single daily bolus did not keep serum magnesium trough levels elevated. Because the results showed a potential dosedependent benefit, a second experiment was performed with two groups; high dose infusion $(2.4 \mathrm{mM})$ combined with 2 daily injections of $\mathrm{MgSO}_{4}$ (total dose $8.2 \mathrm{mM} / \mathrm{kg} / \mathrm{d}$ ) compared with saline infusion/bolus control. The rats in this experiment were injected with kaolin 1 wk earlier (average weight 52.7g) than in the first experiment.

Behavioral testing. The outcome measures and testing protocols are the same as those described in prior drug treatments of young rats with hydrocephalus (13). All testing was done in a blinded manner. The rats were weighed twice per week. On a weekly basis, beginning before kaolin injection in experiment 1 , or after kaolin injection in experiment 2, several specific behavioral tests were performed. The rats were always tested in the same order and a given rat was tested at the same time of the day from week to week.

On the first testing day of each week, swimming speed was tested in a 20 -cm-deep 15 -cm-wide water trough by measuring the time to swim $150 \mathrm{~cm}$. Memory was then assessed in a modified water maze test using a $90-\mathrm{cm}$ pool (filled with $22^{\circ} \mathrm{C}$ opacified water) that contained a $13-\mathrm{cm}$-round hidden platform $1 \mathrm{~cm}$ below the water surface as previously described $(14,19)$. Testing took place in a dimly lit room with a single wall illuminated to provide directional cues. The rats were placed in the center of the pool and allowed to swim until they found the platform. A trial consisted of four attempts to find the platform, each attempt beginning with the rat facing a different quadrant. If the rat failed to complete the task in $60 \mathrm{~s}$, it was given a 30-s rest period before the next attempt. Three trials were performed during the course of the day; each was separated by a 3-h interval. The times of the 4 attempts were averaged for each trial.

On the second testing day of each week, the rats were observed in an open field situation for a period of $1 \mathrm{~min}$ to assess arousal, grooming, and gait by using a previously validated set of parameters (20). Quantitative monitoring of spontaneous activity was then performed for $10 \mathrm{~min}$ in a square enclosure $(43 \times 43 \mathrm{~cm})$ with 15 infrared beams (spaced every $3 \mathrm{~cm}$ ) along the floor in each of two horizontal directions and a third set of similarly spaced beams $8.5 \mathrm{~cm}$ above the floor (Opto-Varimex; Columbus Instruments, Columbus $\mathrm{OH}$, U.S.A.). Vertical, total, and ambulatory beam breaks were counted, the latter being defined as an interruption in a series of adjacent beams. Finally, gait agility was assessed using a rotating cylinder (7-cm diameter) (Economex, Columbus Instruments) in 2 separate trials. First, endurance at a constant speed of $5 \mathrm{rpm}$ was assessed for a maximum of $2 \mathrm{~min}$. Second, we measured the ability to stay on the cylinder, which accelerated beginning at $2.5 \mathrm{rpm}$ and increasing at a rate of $0.1 \mathrm{rpm}$ every second for up to $2 \mathrm{~min}$. The time was recorded from the moment the rat was placed on the rotating cylinder until it fell off. The rotating cylinder test is complex and involves proprioceptive, tactile, vestibular, and motor functions.

Histopathological and biochemical studies of brains following drug treatments. At the end of the 2-wk drug treatment period and following the final MR imaging session, the rats were given an overdose of ketamine/xylazine (90:5 mg/kg), blood was drawn for magnesium level analysis, the vascular system cleared by transcardiac perfusion with ice-cold $0.1 \mathrm{M}$ PBS, and the brains were removed quickly. The cerebral hemispheres were spread apart to facilitate dissection of the corpus callosum from one side. Samples of the corpus callosum, parietal and frontal cerebrum, hippocampus, and cerebellum were dissected and frozen in liquid nitrogen, after which they were stored at $-80^{\circ} \mathrm{C}$. The remaining pieces were immersion fixed in $10 \%$ buffered formalin. The anterior cerebrum, cut coronally at the level of the optic chiasm, was 
embedded in paraffin. Sections (6 $\mu \mathrm{m}$ thickness) were stained with solochrome cyanine for visualization of myelin. Corpus callosum thickness was measured in the midline and adjacent to the cingulum. As described previously in detail $(21,22)$, frontal cerebrum homogenates were used to quantify glial fibrillary acidic protein (GFAP), synaptophysin, and myelin basic protein (MBP) by using Western blots. Corpus callosum homogenates were used to assay the myelin related enzyme p-nitrophenylphosphorylcholine phosphocholine phosphodiesterase (PNPP), and the oligodendrocyte-related enzyme ceramide galactosyltransferase (CGalT) by biochemical means. Two or three replicated studies were performed to ensure reproducibility and allow meaningful statistical analysis.

Statistical analysis. Data are presented as mean \pm SEM. For Western blots, the densitometric values were normalized to those of control values and percent changes relative to control are indicated. They were analyzed by nonparametric methods, either Mann-Whitney test or Kruskall-Wallis test as appropriate for the number of groups. Quantitative behavioral data were analyzed to confirm a normal distribution. Statistical analysis then consisted of two-tailed $t$ test or ANOVA with posthoc Fisher least square difference calculations for inter-group comparisons, as appropriate. To take into consideration multiple tests, statistical significance was defined as $p<0.03$. Software used was StatView 5 (SAS Institute; Cary NC, U.S.A.). Power was calculated using the online Power Calculator tool (http://ebook.stat.ucla.edu/calculators/powercalc/).

\section{RESULTS}

Experiment 1. For the final analysis 24 rats were used $(8$ saline, 8 low dose, 8 high dose). Excluded from the analysis were 1 rat that died during kaolin injection, 5 that died of uncertain cause, and 1 that was euthanized during drug treatment because of severe neurologic deficits. There was no obvious adverse effect of the $\mathrm{MgSO}_{4}$ in these rats. The average pretreatment serum $\mathrm{Mg}^{++}$level was $1.13 \pm 0.01 \mathrm{mM} / \mathrm{L}$. Samples taken the day of sacrifice showed that $\mathrm{Mg}^{++}$levels were high $(>7 \mathrm{mM} / \mathrm{L})$ for only the first $120 \mathrm{~min}$ (Fig. 3).

Morphologic and biochemical analysis of brains from hydrocephalic rats at the end of the experiment revealed no statistically significant difference between the groups for body weight, ventricle size, PNPP, CGalT, MBP, and synaptophysin (Table 1). The high dose group $(4.1 \mathrm{mM} / \mathrm{kg} / \mathrm{d})$ performed better on the accelerating rotating cylinder $(p=0.0248)$ and tended to perform better on the continuous speed cylinder and in the water maze test (Figs. 4 and 5). Corpus callosum thickness showed a trend in improvement. The power of these tests is in the range of $0.25-0.30$; to increase the power to 0.80 would require sample size of $\sim 35$ per group. There was a statistically significant reduction in reactive gliosis as indicated by GFAP content in the frontal cerebrum $(p<0.02)$.

Experiment 2. We conducted the second experiment to determine whether higher $\mathrm{MgSO}_{4}$ doses $(8.2 \mathrm{mM} / \mathrm{kg} / \mathrm{d})$ could protect rats more effectively. For the final analysis 21 rats were used (4 nonhydrocephalic control, 10 saline, 7 high dose). Excluded from this experiment were 2 rats that died during kaolin injections, 1 that died of unknown cause during drug treatment, 3 that were euthanized before drug treatment, and 3 that were euthanized during drug treatment due to severe neurologic deficits. Also, 2 rats that we thought were likely to die due to severe early neurologic deficits were treated in an unblinded manner with high dose $\mathrm{MgSO}_{4}$. One of these rats survived until the end of the experiment, however, neither are included in the final analysis. The high dose $\mathrm{MgSO}_{4}$ injections were associated with profound lethargy and sedation for $1-2 \mathrm{~h}$ after the boluses. In contrast to experiment 1 , serum $\mathrm{Mg}^{++}$ levels were significantly elevated $(p<0.02)$ in the treated group in the early trough phase, $3-6 \mathrm{~h}$ after the bolus.

Morphologic and biochemical analysis of brains from hydrocephalic rats at the end of the experiment revealed no statistically significant difference between the groups for any of the parameters tested (Table 2). The treated group had a tendency to perform worse on the rotating cylinder; the sedative effect of the $\mathrm{MgSO}_{4}$ likely played a role. The GFAP protein quantity tended to decrease in the high dose $\mathrm{MgSO}_{4}$ group.

\section{DISCUSSION}

These experiments using young rats with kaolin-induced hydrocephalus show that $\mathrm{MgSO}_{4}$ treatment, in a dosedependent manner, has a mild protective effect, but that high doses are associated with adverse effects, particularly sedation. The serum concentrations of $\mathrm{Mg}^{++}$achieved here have previously been shown to be associated with increased levels of $\mathrm{Mg}^{++}$in brain tissue (23). $\mathrm{MgSO}_{4}$ treatment can inhibit the intracellular $\mathrm{Ca}^{++}$increase following experimental head trauma (24) and can protect the traumatized brain when administered as late as $24 \mathrm{~h}$ after the injury $(25,26)$. We have previously shown that calcium-activated proteolysis (activated calpain) is associated with the axonal injury in experimental hydrocephalus (3). Therefore $\mathrm{Mg}^{++}$might prevent activation of calpains by antagonizing $\mathrm{Ca}^{++}$movements into damaged axons. Alternately, like nimodipine, which is protective to a greater degree than $\mathrm{MgSO}_{4}$ in this experiment (13), $\mathrm{Mg}^{++}$ might enhance cerebral blood flow (10), thereby reducing the

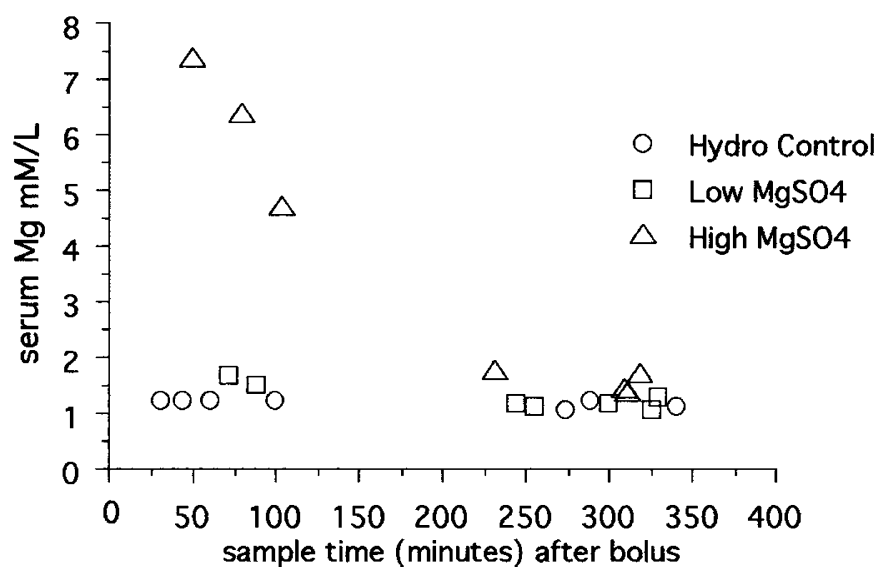

Figure 3. Scatter plot showing serum $\mathrm{Mg}^{++}$levels taken at different times after last injection of $\mathrm{MgSO}_{4}$ or vehicle control in experiment $1 . \mathrm{Mg}^{++}$levels were substantially elevated for $120 \mathrm{~min}$, and returned to normal levels by 230 $\min$. 
Table 1. Results of magnesium sulfate treatment in hydrocephalic rats (experiment 1)

\begin{tabular}{|c|c|c|c|}
\hline & $\begin{array}{l}\text { Control saline } \\
(4.1 \mathrm{mM} / \mathrm{kg} / \text { day })\end{array}$ & 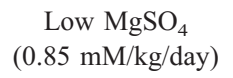 & $\begin{array}{c}\mathrm{High} \mathrm{MgSO}_{4} \\
(4.1 \mathrm{mM} / \mathrm{kg} / \text { day })\end{array}$ \\
\hline Sample size & 8 & 8 & 8 \\
\hline Ventricle area index (pre-treatment) & $0.215 \pm 0.045$ & $0.229 \pm 0.044$ & $0.195 \pm 0.016$ \\
\hline Body weight (g) (pre-treatment) & $156 \pm 10$ & $179 \pm 9$ & $174 \pm 8$ \\
\hline Body weight $(\mathrm{g})$ (post-treatment) & $240 \pm 13$ & $269 \pm 13$ & $256 \pm 8$ \\
\hline Swim time (s) $150 \mathrm{~cm}$ (post-treatment) & $15.3 \pm 1.5$ & $13.3 \pm 2.7$ & $10.2 \pm 1.2$ \\
\hline Ambulatory activity (post-treatment) (beam breaks in $15 \mathrm{~min}$ ) & $1670 \pm 464$ & $1472 \pm 429$ & $1022 \pm 238$ \\
\hline Endurance on roller (continuous speed, post-treatment) (s) & $48.7 \pm 16.5$ & $76.7 \pm 21.2$ & $75.6 \pm 21.4$ \\
\hline Endurance on roller (accelerating speed, post-treatment) (s) & $13.6 \pm 7.7$ & $28.6 \pm 9.2$ & $51.6 \pm 14.8^{*}$ \\
\hline Corpus callosum thickness $(\mu \mathrm{m})$ & $134 \pm 39$ & $222 \pm 49$ & $225 \pm 54$ \\
\hline CGalT activity corpus callosum (nM/mg protein/h) & $1.25 \pm 0.27$ & $1.16 \pm 0.11$ & $1.41 \pm .27$ \\
\hline PNPP activity corpus callosum (nM/mg protein/h) & $82.1 \pm 9.0$ & $76.9 \pm 5.0$ & $99.3 \pm 17.8$ \\
\hline
\end{tabular}

All data are expressed as mean \pm standard error of the mean.

$* p=0.0248$ high dose vs. control, ANOVA with post hoc Fisher least square difference test for intergroup comparisons.

$\dagger p=0.0213$ high dose vs. control hydrocephalic, Kruskall-Wallis test for nonparametric data.

Pre-treatment - data obtained immediately before starting drug treatment, 2 weeks after kaolin injection $\sim 6$ weeks age.

Post-treatment—data obtained immediately before starting drug treatments, 4 weeks after kaolin injection at $\sim 8$ weeks age.

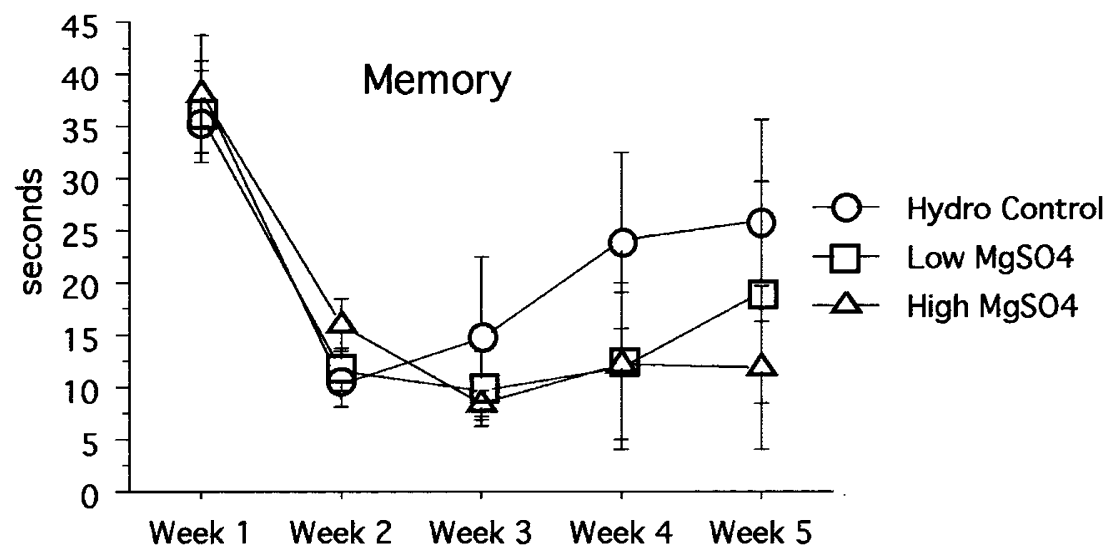

Figure 4. Line graph showing latency times (in seconds) to finding the hidden platform in the water maze test on the first (morning) trial of each weekly assessment in experiment 1 . Week 2 and week 3 correspond to the period of hydrocephalus onset. Drug treatment was administered during week 4 and week 5. At the end of week 5, the high dose $\mathrm{MgSO}_{4}$ group tended to perform better than the untreated hydrocephalic controls $(p=0.3065)$.

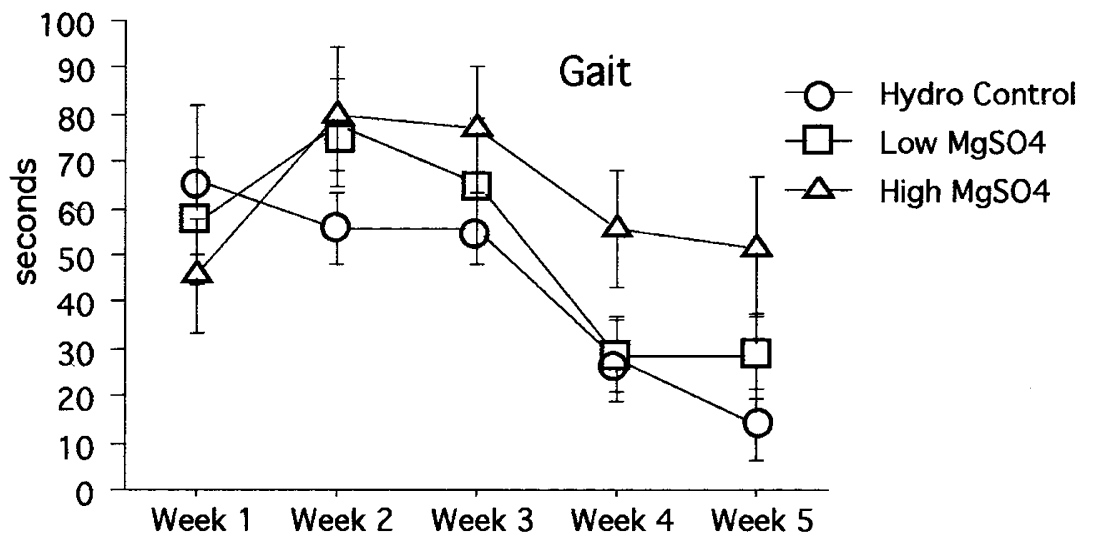

Figure 5. Line graph showing time (in seconds) spent on the accelerating rotating cylinder of each weekly assessment in experiment 1 . In the final week the high dose $\mathrm{MgSO}_{4}$ group performed better than untreated hydrocephalic controls $(p=0.0248)$. 
Table 2. Results of magnesium sulfate treatment on hydrocephalic rats (experiment 2)

\begin{tabular}{|c|c|c|c|}
\hline & $\begin{array}{c}\text { Control saline } \\
(4.1 \mathrm{mM} / \mathrm{kg} \text { twice/day })\end{array}$ & $\begin{array}{c}\mathrm{MgSO}_{4} \\
\text { (4.1 mM/kg twice/day) }\end{array}$ & $\begin{array}{l}\text { Nonhydrocephalic } \\
\text { controls }\end{array}$ \\
\hline Sample size & 10 & 7 & 4 \\
\hline Ventricle area index (pre-treatment) & $0.199 \pm 0.029$ & $0.206 \pm 0.023$ & - \\
\hline Body weight (g) (pre-treatment) & $127 \pm 4$ & $131 \pm 5$ & $148 \pm 11$ \\
\hline Body weight (g) (post-treatment) & $221 \pm 9$ & $231 \pm 11$ & $281 \pm 16$ \\
\hline Swim time (s) $150 \mathrm{~cm}$ (post-treatment) & $15.9 \pm 1.7$ & $19.0 \pm 3.2$ & $14.0 \pm 2.0$ \\
\hline Ambulatory activity (post-treatment) (beam breaks in $15 \mathrm{~min}$ ) & $922 \pm 117$ & $592 \pm 240$ & $1128 \pm 300$ \\
\hline Endurance on roller (continuous speed, post-treatment) (s) & $120 \pm 0.0$ & $67.1 \pm 18.9$ & $119.3 \pm 0.75$ \\
\hline Endurance on roller (accelerating speed, post-treatment) (s) & $75.3 \pm 11.3$ & $55.8 \pm 18.7$ & $90.3 \pm 13.2$ \\
\hline Corpus callosum thickness $(\mu \mathrm{m})$ & $313 \pm 28$ & $296 \pm 25$ & $390 \pm 74$ \\
\hline CGalT activity corpus callosum (nM/mg protein/h) & $2.77 \pm 0.14$ & $2.90 \pm 0.12$ & $2.52 \pm 0.13$ \\
\hline PNPP activity corpus callosum (nM/mg protein/h) & $69.3 \pm 4.1$ & $80.6 \pm 4.3$ & $83.9 \pm 1.1$ \\
\hline
\end{tabular}

All data are expressed as mean \pm standard error of the mean.

$* p<0.0001$ normal rats vs. both hydrocephalic groups, ANOVA with post hoc Fisher least square difference test for intergroup comparisons.

$\dagger 300$ min following last bolus.

$\ddagger p<0.02$ high dose $\mathrm{MgSO}_{4}$ vs. control hydrocephalic, Student $t$ test.

white matter damage caused by hydrocephalus. In both trials, $\mathrm{MgSO}_{4}$ treated hydrocephalic rats had reduced GFAP content in the cerebrum, suggesting that there was less reactive astroglial change due to hydrocephalus (1). It is possible that this is due to a reduced axon injury stimulus, or perhaps it reflects a direct effect of $\mathrm{Mg}^{++}$on astrocytes; in culture $\mathrm{Mg}^{++}$causes increased proliferation of glial precursors but not mature astrocytes (27), and $\mathrm{Mg}^{++}$can modulate amino acid fluxes in astrocytes (28).

An obvious shortcoming of this experiment was that $\mathrm{MgSO}_{4}$ at high doses caused sedation in the rats. This may have obscured a protective effect on behavior. However, we did not observe structural or biochemical protection therefore this dose was likely without benefit. We do not know if the protection conferred by $\mathrm{MgSO}_{4}$ is permanent. It would be useful to determine the effect by extending the experiment following discontinuation of the drug; however, because hydrocephalus is progressive new damage would be incurred. The reverse experiment, in which hydrocephalic rats are deprived of dietary $\mathrm{Mg}^{++}$would also be of use for understanding interactions with $\mathrm{Ca}^{++}$. Direct measurements of brain $\mathrm{Mg}^{++}$would help interpretation of all these experiments.

In conclusion, we find that $\mathrm{MgSO}_{4}$ provides mild protection against brain damage in a rat model of childhood-onset hydrocephalus. However, we cannot recommend this for therapy in humans at this time. It should be noted that a recent study showed antenatal $\mathrm{MgSO}_{4}$ in preterm labor was associated with adverse neurologic outcome, in contrast to expectations (29). We will continue to explore pharmacological approaches that might be used as a supplement to shunt treatment of hydrocephalus.

Acknowledgment. We thank Dr. R. Buist for assistance in the MR imaging.

\section{REFERENCES}

1. Del Bigio MR 1993 Neuropathological changes caused by hydrocephalus. Acta Neuropathol (Berl) 85:573-585

2. McAllister JP, II, Chovan P 1998 Neonatal hydrocephalus. Mechanisms and consequences. Neurosurg Clin N Am 9:73-93

3. Del Bigio MR 2000 Calcium-mediated proteolytic damage in white matter of hydrocephalic rats? J Neuropathol Exp Neurol 59:946-954

4. Simpson JI, Eide TR, Schiff GA, Clagnaz JF, Hossain I, Tverskoy A, Koski G 1994 Intrathecal magnesium sulfate protects the spinal cord from ischemic injury during thoracic aortic cross-clamping. Anesthesiology 81:1493-1499

5. Marinov MB, Harbaugh KS, Hoopes PJ, Pikus HJ, Harbaugh RE 1996 Neuroprotective effects of preischemia intraarterial magnesium sulfate in reversible focal cerebral ischemia. J Neurosurg 85:117-124

6. Suzer T, Coskun E, Islekel H, Tahta K 1999 Neuroprotective effect of magnesium on lipid peroxidation and axonal function after experimental spinal cord injury. Spinal Cord 37:480-484

7. Sameshima H, Ikenoue T 2001 Long-term magnesium sulfate treatment as protection against hypoxic-ischemic brain injury in seven-day-old rats. Am J Obstet Gynecol 184:185-190

8. Vink R, Nimmo AJ, Cernak I 2001 An overview of new and novel pharmacotherapies for use in traumatic brain injury. Clin Exp Pharmacol Physiol 28:919-921

9. Hoane MR, Barth TM 2001 The behavioral and anatomical effects of $\mathrm{MgCl}_{2}$ therapy in an electrolytic lesion model of cortical injury in the rat. Magnes Res $14: 51-63$

10. Brewer RP, Parra A, Lynch J, Chilukuri V, Borel CO 2001 Cerebral blood flow velocity response to magnesium sulfate in patients after subarachnoid hemorrhage. J Neurosurg Anesthesiol 13:202-206

11. Nelson KB, Grether JK 1995 Can magnesium sulfate reduce the risk of cerebral palsy in very low birthweight infants? Pediatrics 95:263-269

12. Massicotte EM, Buist R, Del Bigio MR 2000 Altered diffusion and perfusion in hydrocephalic rat brain: a magnetic resonance imaging analysis. J Neurosurg 92:442447

13. Del Bigio MR, Massicotte EM 2001 Protective effect of nimodipine on behavior and white matter of rats with hydrocephalus. J Neurosurg 94:788-794

14. Del Bigio MR, Crook CR, Buist R 1997 Magnetic resonance imaging and behavioral analysis of immature rats with kaolin-induced hydrocephalus: pre- and postshunting observations. Exp Neurol 148:256-264

15. Galvin KA, Oorschot DE 1998 Postinjury magnesium sulfate treatment is not markedly neuroprotective for striatal medium spiny neurons after perinatal hypoxia/ ischemia in the rat. Pediatr Res 44:740-745

16. Hallak M, Berman RF, Irtenkauf SM, Janusz CA, Cotton DB 1994 Magnesium sulfate treatment decreases N-methyl-D-aspartate receptor binding in the rat brain: an autoradiographic study. J Soc Gynecol Investig 1:25-30

17. Kaya M, Kucuk M, Kalayci RB, Cimen V, Gurses C, Elmas I, Arican N 2001 Magnesium sulfate attenuates increased blood-brain barrier permeability during insulin-induced hypoglycemia in rats. Can J Physiol Pharmacol 79:793-798

18. Wolf G, Keilhoff G, Fischer S, Hass P 1990 Subcutaneously applied magnesium protects reliably against quinolinate- induced N-methyl-D-aspartate (NMDA)- 
mediated neurodegeneration and convulsions in rats: are there therapeutical implications. Neurosci Lett 117:207-211

19. Kraemer PJ, Brown RW, Baldwin SA, Scheff SW 1996 Validation of a single-day Morris water maze procedure used to assess cognitive deficits associated with brain damage. Brain Res Bull 39:17-22

20. Moser VC, Tilson HA, MacPhail RC, Becking GC, Cuomo V, Frantik E, Kulig BM, Winneke G 1997 The IPCS Collaborative Study on Neurobehavioral Screening Methods: II. Protocol design and testing procedures. NeuroToxicology 18:929-938

21. Del Bigio MR, Kanfer JN, Zhang YW 1997 Myelination delay in the cerebral white matter of immature rats with kaolin-induced hydrocephalus is reversible. J Neuropathol Exp Neurol 56:1053-1066

22. Del Bigio MR, Zhang YW 1998 Cell death, axonal damage, and cell birth in the immature rat brain following induction of hydrocephalus. Exp Neurol 154:157169

23. Hallak M, Berman RF, Irtenkauf SM, Evans MI, Cotton DB 1992 Peripheral magnesium sulfate enters the brain and increases the threshold for hippocampal seizures in rats. Am J Obstet Gynecol 167:1605-1610
24. Ustun ME, Duman A, Ogun CO, Vatansev H, Ak A 2001 Effects of nimodipine and magnesium sulfate on endogenous antioxidant levels in brain tissue after experimental head trauma. J Neurosurg Anesthesiol 13:227-232

25. Heath DL, Vink R 1999 Optimization of magnesium therapy after severe diffuse axonal brain injury in rats. J Pharmacol Exp Ther 288:1311-1316

26. Heath DL, Vink R 1999 Improved motor outcome in response to magnesium therapy received up to 24 hours after traumatic diffuse axonal brain injury in rats. J Neurosurg 90:504-509

27. Krueger RC Jr, Santore MT, Dawson G, Schwartz NB 2001 Increased extracellular magnesium modulates proliferation in fetal neural cells in culture. Dev Brain Res 127:99-109

28. Philibert RA, Rogers KL, Allen AJ, Dutton GR 1988 Dose-dependent, K+-stimulated efflux of endogenous taurine from primary astrocyte cultures is $\mathrm{Ca} 2+$-dependent J Neurochem 51:122-126

29. Mittendorf R, Dambrosia J, Pryde PG, Lee KS, Gianopoulos JG, Besinger RE, Tomich PG 2002 Association between the use of antenatal magnesium sulfate in preterm labor and adverse health outcomes in infants. Am J Obstet Gynecol $186: 1111-1118$ 